\title{
Preventing the transmission of COVID-19 and other coronaviruses in older adults aged 60 years and above living in long- term care: a rapid review
}

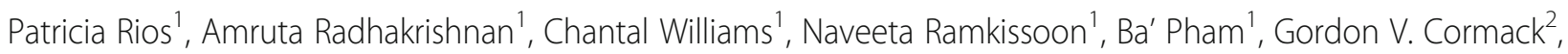
Maura R. Grossman², Matthew P. Muller ${ }^{1,3}$, Sharon E. Straus ${ }^{1,4}$ and Andrea C. Tricco ${ }^{1,5^{*}}$ (i)

\begin{abstract}
Background: The objective of this review was to examine the current guidelines for infection prevention and control (IPAC) of coronavirus disease-19 (COVID-19) or other coronaviruses in adults 60 years or older living in longterm care facilities (LTCF).

Methods: EMBASE, MEDLINE, Cochrane library, pre-print servers, clinical trial registries, and relevant grey literature sources were searched until July 31, 2020, using database searching and an automated method called Continuous Active Learning ${ }^{\oplus}\left(C A L^{\oplus}\right)$. All search results were processed using $C A L^{\oplus}$ to identify the most likely relevant citations that were then screened by a single human reviewer. Full-text screening, data abstraction, and quality appraisal were completed by a single reviewer and verified by a second.

Results: Nine clinical practice guidelines (CPGs) were included. The most common recommendation in the CPGs was establishing surveillance and monitoring systems followed by mandating the use of PPE; physically distancing or cohorting residents; environmental cleaning and disinfection; promoting hand and respiratory hygiene among residents, staff, and visitors; and providing sick leave compensation for staff.
\end{abstract}

Conclusions: Current evidence suggests robust surveillance and monitoring along with support for IPAC initiatives are key to preventing the spread of COVID-19 in LTCF. However, there are significant gaps in the current recommendations especially with regard to the movement of staff between LTCF and their role as possible transmission vectors.

Systematic review registration: PROSPERO CRD42020181993

Keywords: COVID-19, Older adults, Long-term care, Clinical guidelines, Knowledge synthesis

\footnotetext{
*Correspondence: Andrea.tricco@unityhealth.to

${ }^{1}$ Knowledge Translation Program, Li Ka Shing Knowledge Institute, St.

Michael's Hospital, 209 Victoria Street, East Building, Toronto, Ontario M5B

1W8, Canada

${ }^{5}$ Epidemiology Division and Institute for Health Policy, Management, and

Evaluation, Dalla Lana School of Public Health, University of Toronto, Toronto,

Ontario, Canada

Full list of author information is available at the end of the article
}

(c) The Author(s). 2020 Open Access This article is licensed under a Creative Commons Attribution 4.0 International License, which permits use, sharing, adaptation, distribution and reproduction in any medium or format, as long as you give appropriate credit to the original author(s) and the source, provide a link to the Creative Commons licence, and indicate if changes were made. The images or other third party material in this article are included in the article's Creative Commons licence, unless indicated otherwise in a credit line to the material. If material is not included in the article's Creative Commons licence and your intended use is not permitted by statutory regulation or exceeds the permitted use, you will need to obtain permission directly from the copyright holder. To view a copy of this licence, visit http://creativecommons.org/licenses/by/4.0/. The Creative Commons Public Domain Dedication waiver (http://creativecommons.org/publicdomain/zero/1.0/) applies to the data made available in this article, unless otherwise stated in a credit line to the data. 


\section{Introduction}

The current global public health crisis caused by the COVID-19 pandemic has highlighted, among many other things, the critical importance of protecting vulnerable populations from infectious disease. Initial data from the COVID-19 outbreaks in the UK, China, and Italy have shown a significantly increased mortality rate for individuals 60 years of age and above regardless of the presence of comorbid conditions, highlighting the vulnerability of this segment of the population [1-4]. Older adults living in long-term care facilities are especially vulnerable as nosocomial transmission of COVID-19 has been observed in numerous facilities and has contributed to severe outbreaks in healthcare facilities $[5,6]$. Thus, it is crucial at this time to ensure that long-term care facilities have adequate access to information to help them prepare for and respond to potential COVID-19 outbreaks.

\section{Objective and research questions}

The overall objective of this rapid review was to examine the current guidelines for the control and prevention of coronavirus disease-19 (COVID-19), Middle East respiratory syndrome (MERS), and severe acute respiratory syndrome (SARS) in adults 60 years or older living in long-term care facilities:

1. What are the infection prevention and control practices for preventing or reducing the transmission of COVID-19, MERS, or SARS in older adults aged 60 years and above living in long-term care?

2. Do the infection prevention and control practices differ for adults aged 60 years and above living in long-term care with severe comorbidities or frailty differ than those without such severe comorbidities or frailty?

3. What are the employment and remuneration policies that may have contributed to the COVID19 outbreak in adults aged 60 years and above living in long-term care facilities?

\section{Methods}

The conduct of this rapid review was guided by the Rapid Review Guide for Health Policy and Systems [7] published by the World Health Organization (WHO) and reported according to the standards of the PRISMA Checklist [8] (Additional file 1: Appendix 1). A protocol for the review was registered in the PROSPERO database prior to the start of data abstraction (PROSPERO ID: CRD42020181 993). A prior review examining infection control guidelines for any form of viral respiratory illness in long-term care leveraged in this work was commissioned by the World Health Organization and posted on a pre-print server (Supplementary File 2) [9]. The results reported here were shared with the Canadian Frailty Network (review commissioner) in the form of a summary report and onepage brief. Our paper has not been published in a peerreviewed journal.

\section{Search strategy and selection criteria}

In order to accommodate the rapid timeline (10 working days) requested by the review commissioners, a combination of automated and manual search and title/abstract screening methods were used to gather evidence. A comprehensive literature search for the EMBASE database was developed by an experienced librarian and peer-reviewed by a second using the PRESS checklist [10] (Additional file 1: Appendix 2). Grey literature sources (i.e. difficult to locate or unpublished) such as COVID-19-focused evidence gathering services (e.g. EPPI Mapper, COVID-END), as well as guideline producers/repositories (e.g. NICE guidance, ECRI), were hand searched for potentially relevant publications. All other information sources (MEDLINE, Cochrane library, pre-print servers, and clinical trial registries; the full list is available in Additional file 1: Appendix 3) were searched using a supervised machine learning approach, called Continuous Active Learning ${ }^{\oplus}\left(\mathrm{CAL}^{\oplus}\right)$ [11]. All sources were searched from inception up to July 31, 2020.

$\mathrm{CAL}^{\oplus}$ used two methods to gather citations. For sources where the entire archive can be gathered automatically (e.g. MEDLINE), the archive is searched and processed using a priori inclusion criteria established during protocol development. For archives that are only accessible using keyword searches, specific terms drawn from the previously developed literature search (e.g. terms related to COVID-19 and/or long-term care) were applied and the ensuing results were processed using the same inclusion criteria. $\mathrm{CAL}^{\oplus}$ identifies titles and abstracts most likely to meet the inclusion criteria based on an iterative process where search results are compared against relevant citations that have previously been identified. The search results from EMBASE and grey literature sources were compared against the $\mathrm{CAL}^{\oplus}$ results in order to remove duplicates. The results were then screened against the same inclusion criteria by a human reviewer.

All citations that were included by the title/abstract screening process were then passed on to full-text review. A standardized screening form based on the inclusion criteria was developed and calibrated using a pilot test of 10 full-text articles conducted by the review team. A single human reviewer evaluated the full text of each article using the standardized form, and all excluded full-text articles were screened again by a second, independent reviewer. There was full agreement between both reviewers on the excluded articles.

The inclusion criteria established for this rapid review used the PICOS/T framework as follows:

$\triangleright$ Population: Individuals aged 60 years and above residing in long-term care facilities (e.g. nursing home, 
long-term care hospital/facility, skilled nursing facility, convalescent home, assisted living facilities). The definition of long-term care that was used is as follows: "Long-term care homes are home-based health care facilities designed for adults who need access to on-site 24-hour nursing care, frequent assistance with activities of daily living (i.e., eating, bathing, toileting, etc.) and monitoring for safety or wellbeing. They are also known as nursing homes, charitable homes, or municipal homes for the aged" [12, 13].

$>$ Interventions: Any form of infection prevention and control (IPAC), including but not limited to appropriate ventilation, cohorting equipment, communication, consulting/notifying health professionals, diagnostic testing, environmental cleaning/disinfecting surfaces, droplet precautions, education, access to hand hygiene/hand sanitizer, access to personal protective equipment (PPE; for patients and healthcare providers), policies for visitors, IPAC policies for staff/residents and designated IPAC staff, providing supplies, respiratory hygiene/cough etiquette, smoking cessation, social distancing/isolation/cohorting, surveillance/monitoring/evaluation, antiviral prophylaxis for staff/ residents, early mobilization, restrictions on resident movement and transportation, restrictions on visitors, restrictions on travel for healthcare providers, and other long-term care facility staff. Only those measures used to prevent COVID-19, MERS, or SARS were included; measures related to control and prevention of other infections (e.g. vaccination for influenza, oral care to prevent bacterial pneumonia) were excluded. Additionally, interventions related to remuneration/compensation policies for long-term care facility staff, staffing models to maintain staff levels, policies on mixing of staff in long-term care facilities (cohorting), and policies on staff working in more than one long-term care facility were included.

$>$ Comparator: One of the interventions listed above or no intervention

$>$ Outcomes: Lab-confirmed respiratory infection [primary outcome], symptoms, secondary transmission (e.g. other patients, healthcare workers), goal concordant care, hospitalization, intensive care unit (ICU) admission, mortality

$>$ Study designs: clinical practice guidelines (CPGs) and systematic reviews addressing any coronavirus, using the Cochrane definition of a systematic review [14]. Primary human studies of all designs (e.g. experimental studies, quasi-experimental studies, and observational studies, excluding case series) that involved patients with COVID-19 only (not including SARS or MERS) were included.

$>$ Time periods: All periods of time and duration of follow-up were included.

No other limitations were imposed on the search or study selection process. Both peer-reviewed and preprint papers were eligible for inclusion, as were papers written in languages other than English.

\section{Data collection}

A standardized data collection form was developed to capture the following information from primary studies: study characteristics (e.g. duration of follow-up, study design, country of conduct, multi-centre vs. single site), patient characteristics (e.g. mean age, age range, comorbidities), intervention details (e.g. type of intervention, duration and frequency of intervention, timing of intervention), comparator details (e.g. comparator intervention, duration and frequency of intervention, timing of intervention), and outcome results (e.g. lab-confirmed respiratory infection [primary outcome], symptoms, secondary transmission, hospitalization, ICU admission, mortality) at the longest duration of follow-up. A separate standardized form was developed to capture relevant information from clinical practice guidelines, including the method used for the guideline, the intended scope of the guideline, and the specific recommendations and level of evidence for each. All data were collected by a single reviewer and verified by a second, independent reviewer.

\section{Risk of bias appraisal}

Standardized and validated appraisal tools were used to assess the included evidence, namely the AGREE-II tool [15] for clinical practice guidelines, the AMSTAR2 tool [16] for systematic reviews, the Cochrane risk of bias (RoB) tool [17] for randomized studies, and the Newcastle-Ottawa Scale [18] for nonrandomized studies. All appraisals were completed by a single reviewer and verified by a second, independent reviewer.

\section{Synthesis}

As this review was conducted over a very short timeline and incorporated diverse evidence sources, no formal statistical or qualitative analysis was planned. Data from the included studies are summarized narratively and in summary tables and detailed tables of results.

\section{Results \\ Literature search}

The manual searches and automated search and screening process returned a combined total of 628 titles and abstracts for further evaluation. A total of 537 title and abstract citations were then excluded, and 91 articles were passed to full-text screening. A further 85 articles were excluded during full-text screening leaving six included policy guidelines [19-24]. These guidelines were combined with three clinical practice guidelines (CPGs) [25-27] found during an earlier review [9] for a total of 9 articles included in this review (Fig. 1).

\section{Characteristics of included articles}

All of the included guidelines were published in the year 2020 in the USA $(n=5)$, South Africa $(n=1)$, the UK $(n$ 


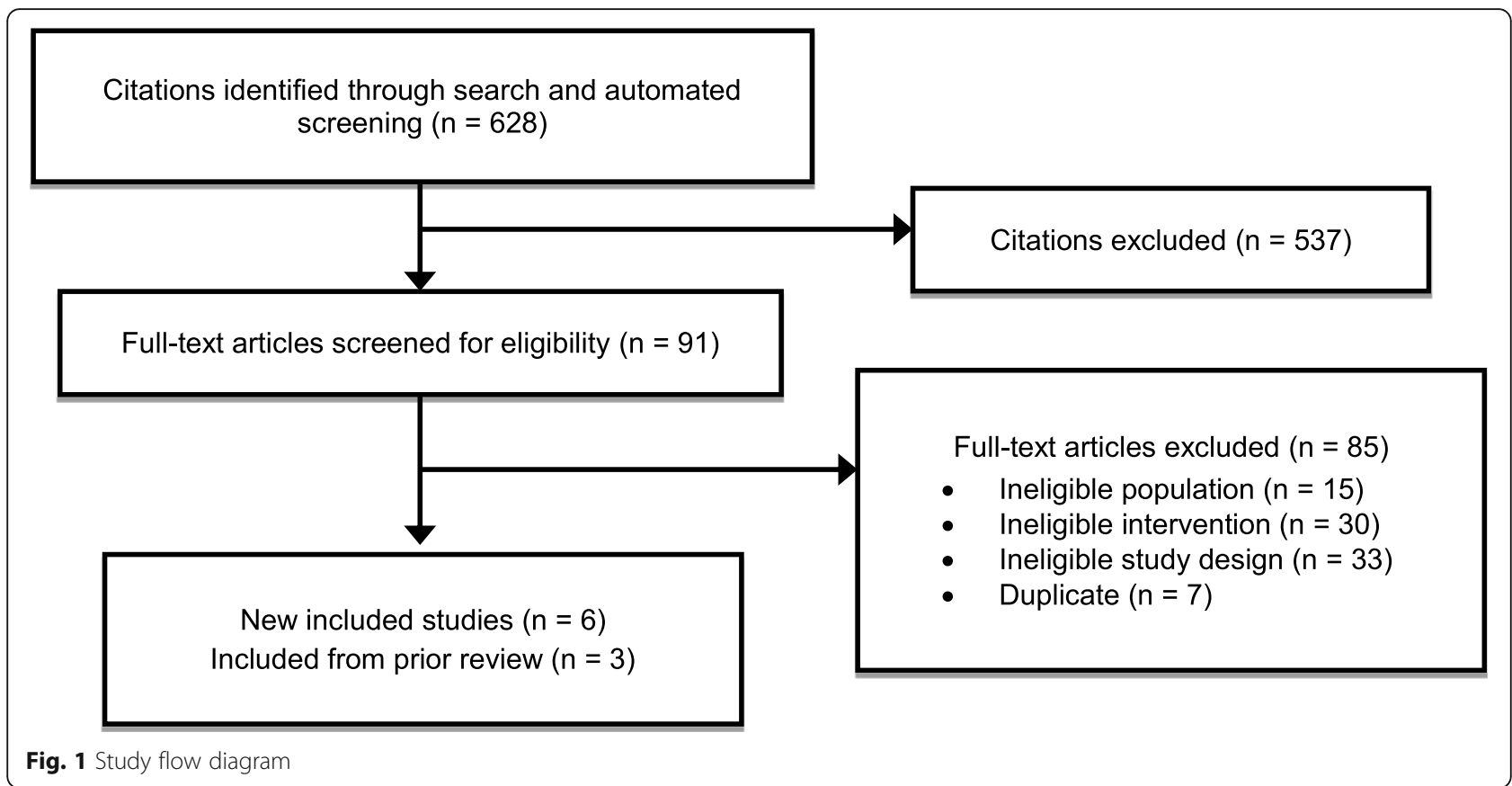

$=1)$, and Canada $(n=1)$. The nine included CPGs were published by government agencies [23, 25, 27] $(n=3)$, medical associations $(n=3)[19,22,24]$, non-profit research trusts $[20,26](n=2)$, or international health organizations $(n=1)$ [21]; target audiences included administration, staff, residents, and visitors of long-term care facilities of any type (Additional file 1: Appendix 4).

The nine included clinical practice guidelines were of very low quality as they reported very few items across the assessment domains (Table 1; full results in Additional file 1: Appendix 5). For the scope and purpose domain, the clinical practice guidelines reported two to six of the relevant details out of 12 . For the stakeholder domain, the guidelines reported one to six of the relevant details out of 11. For the rigour of the development domain, only two guidelines reported one relevant detail out of 35 items. For the clarity of the presentation domain, the guidelines reported two to seven of the relevant details out of eight. For the applicability domain, five guidelines each reported one of the relevant details out of 13 . For the editorial independence domain, the guidelines reported 0 to two of the relevant details out of six.

\section{CPG recommendations}

The included CPGs recommended a variety of interventions that were summarized into 16 general categories (Table 2; Additional file 1: Appendices 6 and 7). The most common recommendation was establishing surveillance, monitoring, and evaluation of symptoms/illness among staff and residents, present in eight of the nine included CPGs. The next most frequent recommendations were included in five or more CPGs: mandating the use of appropriate personal protective equipment (PPE) for staff, residents, and/or visitors; employing social distancing or isolation measures to prevent the spread of COVID-19 (e.g. serving resident meals in individual rooms, cancelling group activities in the facility) and/or cohorting (isolating) patients with confirmed or suspected COVID-19; routine or increased disinfection of surfaces in the facility; promoting and enforcing hand-hygiene measures among staff, residents, and/or visitors; promoting and enforcing respiratory hygiene measures among staff, residents, and/or visitors; and implementing staffing policies to promote and enforce mandatory sick leave for staff with symptoms or suspected COVID-19 and/or ensure adequate compensation for staff on sick leave as well as policies to restrict the movement of staff within or between facilities. Other recommendations included in two to four CPGs were ensuring appropriate communication between longterm care facilities and local/regional health authorities; educating staff and/or residents on appropriate infection control, hand, or respiratory hygiene; ensuring adequate supplies of PPE, medications, and other medical equipment (e.g. ventilators) to manage COVID-19 outbreaks; consulting with and notifying relevant health professionals to deal with COVID-19 cases; policies restricting visitor hours or limiting to "essential" visitors only; and mandating the use of droplet precautions (including appropriate PPE) when treating any patient suspected or confirmed to have COVID-19. Finally, the following recommendations were only included in one CPG each: cohorting certain equipment to only be used with COVID-19 patients and testing all symptomatic staff and/or residents for COVID-19. 
Table 1 Summary AGREE-II scores

\begin{tabular}{|c|c|c|c|c|c|c|c|c|c|}
\hline & $\begin{array}{l}\text { AGS, } \\
2020[19]\end{array}$ & $\begin{array}{l}C D C \\
2020[25]\end{array}$ & $\begin{array}{l}\text { ECRI, } \\
2020 \mathrm{a} \\
{[26]}\end{array}$ & $\begin{array}{l}\text { ECRI, } \\
2020 \mathrm{~b} \\
{[20]}\end{array}$ & $\begin{array}{l}\text { Geffen, } \\
2020\end{array}$ & $\begin{array}{l}\text { HPS, } \\
2020 \\
{[23]}\end{array}$ & $\begin{array}{l}\text { Lester, } \\
2020[24]\end{array}$ & $\begin{array}{l}\text { MOH, } \\
2020[27]\end{array}$ & $\begin{array}{l}\text { WHO, } \\
2020[21]\end{array}$ \\
\hline \multicolumn{10}{|c|}{ Domain 1: Scope and purpose (12 points in total) } \\
\hline Item 1: Objectives & 3 & 2 & 1 & 1 & 1 & 2 & 2 & 2 & 1 \\
\hline Item 2: Questions & 1 & 1 & 1 & 1 & 0 & 0 & 0 & 1 & 0 \\
\hline Item 3: Population & 2 & 1 & 2 & 1 & 1 & 2 & 2 & 1 & 2 \\
\hline Totals & 6 & 4 & 4 & 3 & 2 & 4 & 4 & 4 & 3 \\
\hline \multicolumn{10}{|c|}{ Domain 2: Stakeholder involvement (11 points in total) } \\
\hline Item 4: Group membership & 1 & 0 & 0 & 0 & 0 & 1 & 3 & 0 & 0 \\
\hline $\begin{array}{l}\text { Item 5: Target population } \\
\text { preferences and views }\end{array}$ & 0 & 0 & 0 & 0 & 0 & 0 & 2 & 0 & 0 \\
\hline Item 6: Target users & 1 & 1 & 0 & 1 & 2 & 1 & 1 & 1 & 1 \\
\hline Totals & 2 & 1 & 0 & 1 & 2 & 2 & 6 & 1 & 1 \\
\hline \multicolumn{10}{|c|}{ Domain 3: Rigour of development (35 points in total) } \\
\hline Item 7: Search methods & 0 & 0 & 0 & 0 & 0 & 0 & 1 & 0 & 0 \\
\hline Item 8: Evidence selection criteria & 0 & 0 & 0 & 0 & 0 & 0 & 0 & 0 & 0 \\
\hline $\begin{array}{l}\text { Item 9: Strengths and limitations of } \\
\text { the evidence }\end{array}$ & 0 & 0 & 0 & 0 & 0 & 0 & 0 & 0 & 0 \\
\hline $\begin{array}{l}\text { Item 10: Formulation of } \\
\text { recommendations }\end{array}$ & 0 & 0 & 0 & 1 & 0 & 0 & 0 & 0 & 0 \\
\hline $\begin{array}{l}\text { Item 11: Consideration of benefits } \\
\text { and harms }\end{array}$ & 0 & 0 & 0 & 0 & 0 & 0 & 0 & 0 & 0 \\
\hline $\begin{array}{l}\text { Item 12: Link between } \\
\text { recommendations and evidence }\end{array}$ & 0 & 0 & 0 & 0 & 0 & 0 & 0 & 0 & 0 \\
\hline Item 13: External review & 0 & 0 & 0 & 0 & 0 & 0 & 0 & 0 & 0 \\
\hline Item 14: Updating procedure & 0 & 0 & 0 & 0 & 1 & 0 & 0 & 0 & 0 \\
\hline Totals & 0 & 0 & 0 & 1 & 1 & 0 & 1 & 0 & 0 \\
\hline \multicolumn{10}{|c|}{ Domain 4: Clarity of presentation (8 points in total) } \\
\hline $\begin{array}{l}\text { Item 15: Specific and unambiguous } \\
\text { recommendations }\end{array}$ & 3 & 3 & 3 & 1 & 2 & 2 & 3 & 2 & 1 \\
\hline Item 16: Management options & 0 & 0 & 2 & 1 & 1 & 1 & 1 & 1 & 1 \\
\hline $\begin{array}{l}\text { Item 17: Identifiable key } \\
\text { recommendations }\end{array}$ & 0 & 1 & 2 & 0 & 2 & 2 & 2 & 1 & 1 \\
\hline Totals & 3 & 4 & 7 & 2 & 5 & 5 & 6 & 4 & 3 \\
\hline \multicolumn{10}{|l|}{ Domain 5: Applicability (13 points in total) } \\
\hline $\begin{array}{l}\text { Item 18: Facilitators and barriers to } \\
\text { application }\end{array}$ & 0 & 0 & 0 & 0 & 0 & 0 & 0 & 0 & 0 \\
\hline $\begin{array}{l}\text { Item 19: Implementation advice/ } \\
\text { tools }\end{array}$ & 0 & 1 & 0 & 1 & 1 & 1 & 0 & 1 & 0 \\
\hline Item 20: Resource implications & 0 & 0 & 0 & 0 & 0 & 0 & 0 & 0 & 0 \\
\hline $\begin{array}{l}\text { Item 21: Monitoring/auditing } \\
\text { criteria }\end{array}$ & 0 & 0 & 0 & 0 & 0 & 0 & 0 & 0 & 0 \\
\hline Totals & 0 & 1 & 0 & 1 & 1 & 1 & 0 & 1 & 0 \\
\hline \multicolumn{10}{|c|}{ Domain 6: Editorial independence (6 points in total) } \\
\hline Item 22: Funding body & 1 & 1 & 1 & 0 & 0 & 1 & 2 & 1 & 1 \\
\hline Item 23: Competing interests & 1 & 0 & 0 & 0 & 0 & 0 & 0 & 0 & 0 \\
\hline Totals & 2 & 1 & 1 & 0 & 0 & 1 & 2 & 1 & 1 \\
\hline
\end{tabular}


Table 2 Summary of recommendations from included clinical practice guidelines

\begin{tabular}{|c|c|c|c|c|c|c|c|c|c|}
\hline Recommendations & $\begin{array}{l}\text { AGS, } 2020 \\
{[19]}\end{array}$ & $\begin{array}{l}\text { CDC, } 2020 \\
{[25]}\end{array}$ & $\begin{array}{l}\text { ECRI, } \\
\text { 2020a [26] }\end{array}$ & $\begin{array}{l}\text { ECRI, } \\
2020 \mathrm{~b}[20]\end{array}$ & $\begin{array}{l}\text { Geffen, } \\
2020\end{array}$ & $\begin{array}{l}\text { HPS, } 2020 \\
{[23]}\end{array}$ & $\begin{array}{l}\text { Lester, } \\
2020[24]\end{array}$ & $\begin{array}{l}\text { MOH, } \\
2020[27]\end{array}$ & $\begin{array}{l}\text { WHO, } \\
2020[21]\end{array}$ \\
\hline Cohorting equipment & & & $x$ & & & & & & \\
\hline Communication & & & & $x$ & & $x$ & $x$ & & $x$ \\
\hline $\begin{array}{l}\text { Consulting/notifying health } \\
\text { professionals }\end{array}$ & $x$ & & $x$ & & & & & $x$ & \\
\hline Diagnostic testing & & & & & & & & $x$ & \\
\hline Disinfecting surfaces & & $x$ & $x$ & & $x$ & $x$ & & $x$ & $x$ \\
\hline Droplet precautions & & & & & & & & $x$ & $x$ \\
\hline Education & $x$ & $x$ & & $x$ & & & & & $x$ \\
\hline Hand hygiene & & $x$ & $x$ & & $x$ & $x$ & & $x$ & \\
\hline $\begin{array}{l}\text { Personal protective } \\
\text { equipment }\end{array}$ & & $x$ & $x$ & & $x$ & $x$ & $x$ & $x$ & $x$ \\
\hline Policies for visitors & & $x$ & & & $x$ & & & $x$ & \\
\hline Provide supplies & $x$ & $x$ & & $x$ & $x$ & & & & \\
\hline $\begin{array}{l}\text { Respiratory hygiene/cough } \\
\text { etiquette }\end{array}$ & & $x$ & & $x$ & $x$ & $x$ & & $x$ & \\
\hline $\begin{array}{l}\text { Social distancing/isolation/ } \\
\text { cohorting }\end{array}$ & $x$ & $x$ & $x$ & & $x$ & $x$ & $x$ & & $x$ \\
\hline Staffing policies & $x$ & $x$ & & & $x$ & $x$ & & $x$ & \\
\hline $\begin{array}{l}\text { Surveillance/monitoring/ } \\
\text { evaluation }\end{array}$ & $x$ & $x$ & & $x$ & $x$ & $x$ & $x$ & $x$ & $x$ \\
\hline
\end{tabular}

\section{Discussion}

This rapid review aimed to address the question of what are effective IPAC measures for COVID-19 that can be used in long-term care. It is especially relevant given the current COVID-19 outbreaks in such facilities globally including the UK and Canada. A comprehensive literature search that included electronic sources, grey literature sites, and references from a prior review produced nine clinical practice guidelines dealing specifically with the control and management of COVID-19 and SARS among older adults in long-term care. None of the included articles addressed MERS or infection control and prevention for frail older adults or those with significant comorbidity. Only five of the included CPGs addressed how compensation or leave policies or policies restricting staff to one work location could affect the transmission of COVID-19 in long-term care facilities.

Among the nine included CPGs, the most commonly recommended strategy was establishing surveillance, monitoring, and evaluation within long-term care facilities, followed by mandating the use of PPE, employing physical distancing/isolation or cohorting measures among residents of a facility, disinfecting surfaces, promoting hand hygiene, promoting respiratory hygiene/cough etiquette, implementing policies regarding staff sick leave or restricting staff movement, establishing clear communication means and consulting with or notifying relevant healthcare authorities and ensuring appropriate action is taken, educating staff and/or residents on infection control and hygiene, ensuring adequate supplies for facilities, mandating droplet precautions, and policies restricting visitors to long-term care. It should be noted however that many of the included guidelines were prepared as rapid responses to an urgent situation and thus had to forgo more formal guideline development methods in favour of expedience. In this particular case, low appraisal scores should not necessarily be indicative of untrustworthy recommendations. However, as these recommendations have not gone through the rigorous process of formal guideline development neither should they be taken at face value as they may not reflect the best available evidence.

The gaps in evidence that this review has identified are particularly important. For example, much has been written about how personal support workers or care home providers are underpaid and often have to work across multiple institutions [3]. However, there is a paucity of literature on how compensation models for healthcare workers in longterm care could impact outbreaks. Moreover, while the identified guidelines recommend various strategies including adequate PPE use, one of the common global challenges has been supply chain shortages. This issue highlights that practical or technological barriers to implementing guideline recommendations must also be considered. Furthermore, the majority of existing IPAC guidelines relevant to longterm care facilities focus on managing viral outbreaks caused by influenza and emphasize the use of vaccination or chemoprophylaxis, both of which are options not currently available in the control of COVID-19 or other coronaviruses 
[9]. The most up-to-date knowledge base for prevention and control of COVID-19 is likely not in guidelines specifically tailored to long-term care but rather acute or hospital settings, highlighting the fact that long-term care facilities need substantial additional support and resources to effectively tackle this crisis.

There are several limitations to the review methods employed here primarily the lack of duplicate screening and abstraction. However, these methods were selected to tailor our approach to our knowledge-user needs and satisfy the urgent need to provide timely results. There is also a chance that our literature search missed guidance documents from various state and provincial authorities that address IPAC in other types of healthcare facilities (e.g. hospitals or acute care) that could be successfully applied to long-term care facilities. However, we were unable to perform an exhaustive grey literature search of guideline repositories and agency websites due to the timelines imposed on this review.

The current guidelines on preventing transmission of COVID-19 in long-term care facilities seem to suggest that robust surveillance and monitoring programs, accompanied with environmental cleaning measures and supporting the use of PPE, hand/respiratory hygiene, and physical distancing, are the ideal approach to protect older adults. However, there are significant gaps in the current recommendations, especially related to the movement of staff between long-term care facilities, as well as an overall lack of guidelines specific to managing highly virulent outbreaks in long-term care facilities.

\section{Supplementary information}

Supplementary information accompanies this paper at https://doi.org/10. 1186/s13643-020-01486-4.

Additional file 1:. Appendices. Appendix 1 - PRISMA Checklist. Appendix 2 - Embase Search Strategy. Appendix 3 - Grey Literature Sources. Appendix 4 - Clinical Practice Guideline Characteristics. Appendix 5 - Detailed Quality Appraisal Results for Clinical Practice Guidelines. Appendix 6 - Clinical Practice Guideline Results. Appendix 7 CPG Coding Summary and Supporting Text

Additional file 2:. Guidelines for preventing respiratory illness in older adults aged 60 years and above living in long-term care: A rapid review of clinical practice guidelines (pre-print report)

\section{Abbreviations}

CAL: Continuous Active Learning; COVID-19: Coronavirus disease-19; CPG: Clinical practice guideline; ICU: Intensive care unit; MERS: Middle East respiratory syndrome; PPE: Personal protective equipment; PRESS: Peer Review of Electronic Search Strategies; SARS: Severe acute respiratory syndrome; WHO: World Health Organization

\section{Acknowledgements}

We would like to thank Dr. Jessie McGowan for her assistance in developing the literature search, Leah M Boulos for assistance with the completion of PRESS, and Katrina Chiu for assistance with formatting the manuscript.

\section{Authors' contributions}

PR screened full-text articles, abstracted and verified data, interpreted results and wrote the manuscript; AR, CW, and NR screened full-text articles, abstracted or verified data, and reviewed the manuscript; BP, GVC, and MG developed and ran the automated search and citation screening process andreviewed the manuscript; MPM reviewed and edited the manuscript; SES and ACT developed the protocol, obtained funding, developed review methods, interpreted results, and edited the manuscript. The authors read and approved the final manuscript.

\section{Funding}

This work was supported by the Canadian Frailty Network (CFN) and conducted through the Strategy for Patient Oriented Research (SPOR) Evidence Alliance. The funders had no influence on the design, conduct, or reporting of this work. This work leverages a previous review (https://www. medrxiv.org/content/10.1101/2020.03.19.20039180v2) that was commissioned and funded by the World Health Organization. The authors alone are responsible for the views expressed in this review, and they do not necessarily represent the decisions, policy, or views of the World Health Organization or CFN.

\section{Availability of data and materials}

The full dataset is available from the corresponding author upon reasonable request.

Ethics approval and consent to participate

Not required.

\section{Consent for publication}

Not applicable.

\section{Competing interests}

All authors do not have any potential (or perceived) conflicts of interest.

\section{Author details}

${ }^{1}$ Knowledge Translation Program, Li Ka Shing Knowledge Institute, St. Michael's Hospital, 209 Victoria Street, East Building, Toronto, Ontario M5B 1W8, Canada. ${ }^{2}$ David R. Cheriton School of Computer Science, University of Waterloo, Waterloo, Ontario, Canada. ${ }^{3}$ Department of Medicine, University of Toronto, Toronto, Ontario, Canada. ${ }^{4}$ Department of Geriatric Medicine, University of Toronto, Toronto, Ontario, Canada. ${ }^{5}$ Epidemiology Division and Institute for Health Policy, Management, and Evaluation, Dalla Lana School of Public Health, University of Toronto, Toronto, Ontario, Canada.

Received: 17 June 2020 Accepted: 17 September 2020

Published online: 25 September 2020

\section{References}

1. Liu K, Chen Y, Lin R, Han K. Clinical features of COVID-19 in elderly patients: a comparison with young and middle-aged patients. J Infect. 2020:80(6): e14-e8

2. Onder G, Rezza G, Brusaferro S. Case-fatality rate and characteristics of patients dying in relation to COVID-19 in Italy. JAMA. 2020;323(18):1775-6.

3. Pollock AM, Clements L, Harding-Edgar L. Covid-19: why we need a national health and social care service. BMJ. 2020:369:m1465.

4. Fisman D, Lapointe-Shaw L, Bogoch I, McCready J, Tuite A. Failing our most vulnerable: COVID-19 and long-term care facilities in Ontario. medRxiv. 2020

5. Zhang Y. The epidemiological characteristics of an outbreak of 2019 novel coronavirus diseases (COVID-19) - China, 2020. CCDC Weekly. 2020;2(8): $113-2$.

6. Wang Y, Wang Y, Chen Y, Qin Q. Unique epidemiological and clinical features of the emerging 2019 novel coronavirus pneumonia (COVID-19) implicate special control measures. J Med Virol. 2020;92(6):568-76.

7. Tricco AC, Langlois EV, Straus SE, editors. Rapid reviews to strengthen health policy and systems: a practical guide. Geneva: World Health Organization; 2017. Licence: CC BY-NC-SA 3.0 IGO.

8. Moher D, Liberati A, Tetzlaff J, Altman DG. Preferred reporting items for systematic reviews and meta-analyses: the PRISMA statement. BMJ. 2009; 339:b2535.

9. Guidelines for preventing respiratory illness in older adults aged 60 years and above living in long-term care: a rapid review of clinical practice guidelines. 
Knowledge Translation Program, Unity Health Toronto. 2020. Available from: https:/www.medrxiv.org/content/10.1101/2020.03.19.20039180v2.

10. McGowan J, Sampson M, Salzwedel DM, Cogo E, Foerster V, Lefebvre C. PRESS peer review of electronic search strategies: 2015 guideline statement. J Clin Epidemiol. 2016;75:40-6.

11. Cormack GG, MR. Technology-assisted review in empirical medicine: Waterloo participation in CLEF eHealth 2018. Waterloo: University of Waterloo; 2018.

12. Health Canada. Long-term facilities-based care Ottawa. Government of Canada: ON; 2004. Available from: https://www.canada.ca/en/health-canada/ services/home-continuing-care/long-term-facilities-based-care.html.

13. Ontario Long Term Care Association. Long-term care services and the application process. Toronto, ON. Available from: https://www.oltca.com/ oltca/OLTCA/Public/LongTermCare/Services.aspx.

14. Cochrane handbook for systematic reviews of interventions (version 6.0). Cochrane. 2019. Available from: www.training.cochrane.org/handbook.

15. Brouwers MC, Kerkvliet K, Spithoff K. The AGREE reporting checklist: a tool to improve reporting of clinical practice guidelines. BMJ. 2016;352:11152.

16. Shea BJ, Reeves BC, Wells G, Thuku M, Hamel C, Moran J, et al. AMSTAR 2: a critical appraisal tool for systematic reviews that include randomised or nonrandomised studies of healthcare interventions, or both. BMJ. 2017;358:44008.

17. Higgins JPT, Altman DG, Gøtzsche PC, Jüni $P$, Moher D, Oxman AD, et al. The Cochrane Collaboration's tool for assessing risk of bias in randomised trials. BMJ. 2011;343:d5928.

18. Wells G, Shea B, O'Connell D, Peterson J, Welch V, Losos M, et al. The Newcastle-Ottawa scale (NOS) for assessing the quality of non-randomized studies in meta-analysis. 2000. Available from: http://www.ohri.ca/programs/ clinical_epidemiology/oxford.asp.

19. American Geriatrics Society. American Geriatrics Society policy brief: COVID19 and nursing homes. J Am Geriatr Soc. 2020;68(5):908-11.

20. ECRI. Preparation is the best protection: lessons from the 2003 SARS outbreak. Health Devices. 2020b. Available from: https://www.ecri.org/ components/HDJournal/Pages/Preparation-Is-the-Best-Protection-2003SARS-Outbreak.aspx?tab=2.

21. World Health Organization. Infection prevention and control guidance for long-term care facilities in the context of COVID-19: interim guidance. Geneva: WHO; 2020

22. Kelly GGL. Guidelines, standard operating procedures and clinical practice preventing and managing COVID-19 infections in long-term care facilities. Cape Town, SA: Sifar Samson Institute for Ageing Research; 2020.

23. Health Protection Scotland. COVID-19: information and guidance for care home settings (version 1.6). Scotland, UK: National Services Scotland; 2020

24. Lester PE, Holahan T, Siskind D, Healy E. Policy recommendations regarding skilled nursing facility management of coronavirus 19 (COVID-19): lessons from New York state. J Am Med Dir Assoc. 2020;21(7):888-92.

25. Centers for Disease Control and Prevention. Interim additional guidance for infection prevention and control for patients with suspected or confirmed COVID-19 in nursing homes. CDC. 2020. Available from: https:/www.cdc gov/coronavirus/2019-ncov/healthcare-facilities/prevent-spread-in-longterm-care-facilities.html.

26. ECRI. Protecting against infectious disease transmission during equipment maintenance: lessons from the 2003 SARS outbreak. Health Devices. 2020a. Available from: https://www.ecri.org/components/HDJournal/Pages/ Equipment-Maintenance-Lessons-from-2003-SARS-Outbreak.aspx.

27. Ministry of Health (MOH). COVID-19 guidance: long-term care homes Government of Ontario. 2020. Available from: http://www.health.gov.on.ca/ en/pro/programs/publichealth/coronavirus/docs/2019_long_term_care_ guidance.pdf.

\section{Publisher's Note}

Springer Nature remains neutral with regard to jurisdictional claims in published maps and institutional affiliations.

Ready to submit your research? Choose BMC and benefit from:

- fast, convenient online submission

- thorough peer review by experienced researchers in your field

- rapid publication on acceptance

- support for research data, including large and complex data types

- gold Open Access which fosters wider collaboration and increased citations

- maximum visibility for your research: over $100 \mathrm{M}$ website views per year

At BMC, research is always in progress.

Learn more biomedcentral.com/submissions 